\title{
Sensitivity Analysis on Daylighting, Visual Comfort, and Energy Consumption of Automated Venetian Blinds for Open-Plan Offices in Tropical Climate
}

\author{
Aishanura H. Primanti \\ Engineering Physics \\ Institut Teknologi Bandung \\ Bandung, Indonesia \\ aishanura@students.itb.ac.id \\ R.C.G.M. Loonen \\ Built Environment \\ Eindhoven University of Technology \\ Eindhoven, the Netherlands \\ r.c.g.m.loonen@tue.nl
}

\author{
Rizki A. Mangkuto \\ Engineering Physics \\ Institut Teknologi Bandung \\ Bandung, Indonesia \\ armanto@tf.itb.ac.id \\ Samuel B. de Vries \\ Built Environment \\ Eindhoven University of Technology \\ Eindhoven, the Netherlands \\ s.b.d.vries@tue.nl
}

\author{
M. Donny Koerniawan \\ Architecture \\ Institut Teknologi Bandung \\ Bandung, Indonesia \\ donnykoer@gmail.com
}

\begin{abstract}
This paper presents a comprehensive sensitivity analysis on daylighting, visual comfort, and energy consumption of automated venetian blinds for open-plan offices. This research is using an integrated thermal and lighting simulation model in Grasshopper. The purpose is to identify which factors significantly affect daylighting level, visual comfort, and energy performance of the building. This information can then be used as input for devising an optimal shading control strategy. The investigated shading parameters are blind angle and blind covering area. The performance indicators include Spatial Daylight Autonomy (sDA), Daylight Glare Probability Simplified (DGPs), and Energy Use Intensity (EUI). The sensitivity analysis uses multilinear regression showing the standardized regression coefficient of each shading parameter. The results show that the blind angle has more significant effect compared to the blind covering area for all indicators.
\end{abstract}

Keywords: open-plan office, dynamic shading, venetian blind, DAYSIM, Energy Plus

\section{INTRODUCTION}

Office buildings in tropical climates use $70 \%$ of the energy for space cooling and artificial lighting [1]. The development of open-plan office buildings is, therefore, a common strategy, because of their potential in space-saving and increased energy efficiency [2]. However, modern office buildings façades are dominated by glass. This increases the thermal load of the buildings, while also resulting in higher glare risk for the building occupants $[3,4]$. To mitigate these problems, glare control systems such as dynamic shading devices can be installed. Recently, a sensitivity analysis study for shading devices in a tropical climate has been performed for a classroom with curtains and venetian blinds. However, that study was limited to the evaluation of daylight availability and visual comfort only [5]. In fact, the use of daylighting is closely related to changes in a building's thermal load [6].
Many types of solar shading exist. The most efficient one for the tropical climate is a venetian blind system, which redirects sun rays to minimize glare while controlling the lighting level in the building [7]. Venetian blinds have several parameters that can be controlled, such as the number of slats, slat angle, slat width, blind reflectance, and covering area. Based on the research conducted by Rapone, the most significant parameters are the slat angle and the number of slats [8]. Other research also shows that the shading covering area has a considerable impact on the lighting level on the work plane [5]. Based on these findings, the key parameters that are varied in this study are slat angle and covering area.

This paper presents a sensitivity analysis on daylighting, visual comfort, and energy consumption in an open-plan office. The sensitivity analysis uses standardized multilinear regression to determine which shading parameter has a significant impact on the performance indicator. The result of this paper is essential as a preliminary analysis for dynamic shading device optimization with venetian blind in the openplan office.

\section{METHODS}

\section{A. Simulation Model}

The building model is $43 \mathrm{~m}$ in length and $16 \mathrm{~m}$ in width. This value is extracted typologically from 20 open-plan office buildings in Jakarta, Indonesia. The model is $3 \mathrm{~m}$ tall and has a window-to-wall ratio (WWR) of $80 \%$. The facade is using Low-E glass with a U-value of $4.54 \mathrm{~W} / \mathrm{m}^{2} \mathrm{~K}$, SHGC of 0.4 , and visible transmittance of 0.57 . The building has a core located in the center. The orientation that is evaluated is the west side since it receives the most sunlight exposure in a day (Fig. 1). Shading parameters that are varied are blind angle 
(Fig. 2) and blind covering area (Fig.3). The details of shading design parameter can be seen in Table I.

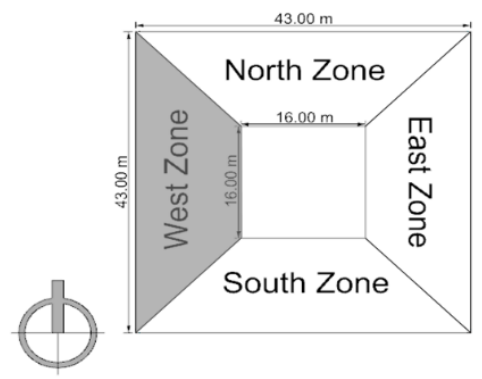

Fig. 1. Model top elevation

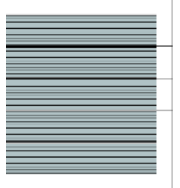

(a)

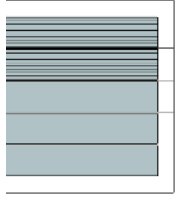

(d)

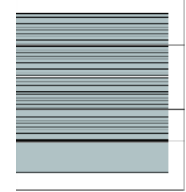

(b)

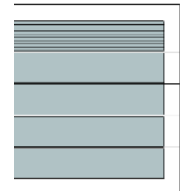

(e)
Fig. 2. Blind covering area (a) $100 \%$ (b) $80 \%$ (c) $60 \%$ (d) $40 \%$ (e) $20 \%$

$$
\mid \begin{aligned}
& 80^{\circ} \\
& 60^{\circ} \\
& -\quad 40^{\circ} \\
& 20^{\circ} \\
& -20^{\circ} \\
& -40^{\circ} \\
& -60^{\circ} \\
& -80^{\circ}
\end{aligned}
$$

Fig. 3. The blind angle from $-80^{\circ}$ to $80^{\circ}$

TABLE I. SHADING PARAMETER DETAILS

\begin{tabular}{|l|l|l|}
\hline Shading Parameter & \multicolumn{1}{|c|}{ Range } & Interval \\
\hline Blind Angle & $-80^{\circ}-80^{\circ}$ & $20^{\circ}$ \\
\hline Blind Covering Area & $20 \%-100 \%$ & $20 \%$ \\
\hline
\end{tabular}

The HVAC system that is assigned to the model is an ideal load air system with a cooling setpoint of $24^{\circ} \mathrm{C}$ and the internal heat gain values that can be seen in Table II. The lighting fixtures are connected to a daylight sensor, so it can be dimmed when the work plane illuminance exceeds 300 lux.
TABLE II. INTERNAL HEAT GAINS

\begin{tabular}{|l|l|}
\hline \multicolumn{1}{|c|}{ Internal Heat Gain } & \multicolumn{1}{c|}{ Internal Heat Load Value } \\
\hline Equipment & $10 \mathrm{~W} / \mathrm{m}^{2}[9]$ \\
\hline Lighting & $12 \mathrm{~W} / \mathrm{m}^{2}[9]$ \\
\hline Occupants & $0.1 \mathrm{people} / \mathrm{m}^{2}[10]$ \\
\hline Ventilation Rate & $5.5 \mathrm{~L} / \mathrm{s}[10]$ \\
\hline
\end{tabular}

The daylighting metric that is used is spatial daylight autonomy (sDA). It calculates the area that has illuminance above a certain threshold for $50 \%$ time of the year [11]. The preferred criterion for sDA must exceed $75 \%$ for a target illuminance of 300 lux 50\% of the time based on LM-83-12.

The metric that is used to evaluate visual comfort is Daylight Glare Probability Simplified (DGPs). It expresses the glare from daylighting as the simplification of Daylight Glare Probability (DGP) because DGP needs to generate many images to calculate luminance for glare, while DGPs can be calculated from vertical eye illuminance [12]. According to the recommendation by Wienold [13], the maximum DGPs value corresponding to imperceptible glare for the occupant is 0.35 . To measure the energy consumption, the metric is divided into cooling energy and lighting energy by summing the energy usage in a year which is called Energy Use Intensity (EUI).

The model of an open-plan office is developed in the modeling software Grasshopper for Rhinoceros. This software enables the user to create a parametric simulation. Grasshopper also has several plug-ins to increase the flexibility of the simulation. With Honeybee for Grasshopper plug-in, daylighting and energy simulation can be integrated into one interface. The engine for daylighting analysis is using DAYSIM, while energy balance with Energy Plus.

Daylight simulation parameters are adjusted to meet the characteristics of the investigated case study. Since venetian blinds have a fine spatial resolution and multiple interreflections, simulation settings for high complexity cases were used (Table III) [14].

TABLE III. DAYLIGHT SIMULATION PARAMETERS

\begin{tabular}{|l|l|l|l|}
\hline \multicolumn{1}{|c|}{ Parameter } & \multicolumn{1}{|c|}{ Description } & Range & Simulated \\
\hline$-\mathrm{ab}$ & ambient bounces & $0-8$ & 7 \\
\hline$-\mathrm{aa}$ & ambient accuracy & $0-0.5$ & 0.1 \\
\hline $\mathrm{-ar}$ & ambient resolution & $0-512$ & 300 \\
\hline $\mathrm{ad}$ & ambient divisions & $0-4096$ & 1500 \\
\hline$-\mathrm{as}$ & ambient super-samples & $0-1024$ & 100 \\
\hline
\end{tabular}

\section{B. Sensitivity Analysis}

The sensitivity analysis is based on the standardized regression coefficient (SRC) from multilinear regression method. This coefficient measures how many standard deviations a dependent variable will change, per standard deviation increase in the predictor variable [15]. The standardized multilinear regression function can be seen in (1) with $\beta_{1}, \beta_{2}$, and $\beta_{k}$ as SRC.

$$
y=\beta_{1} x_{i 1}+\beta_{2} x_{i 2}+. .+\beta_{k} x_{i k}+\varepsilon_{1} i=0,1,2, \ldots, k
$$

This coefficient has a value between -1 to 1 . If SRC is positive, the output increases when the input increases. While a negative SRC means the output decreases when the input 
increases. As the SRC coefficient becomes larger, it indicates that the input variable causes significant changes to the output [16].

\section{RESULTS}

Fig. 4 presents the SRC of blind covering area and blind angle for EUI cooling. There are many aspects that contribute to cooling energy. From the simulation heat gain analysis, the factor that contributes the most to cooling energy is building envelope with $71 \%$ (Fig. 5).

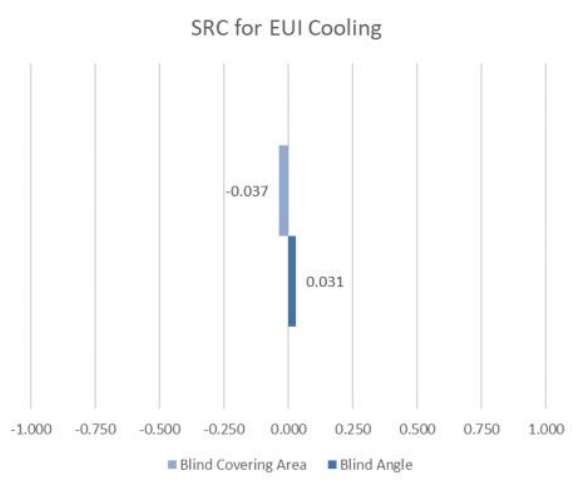

Fig. 4. SRC value for EUI cooling

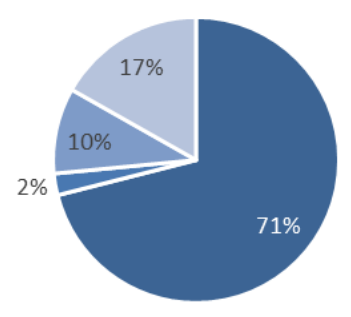

- Building Envelope - Lighting - Electrical Equipment = Occupant

Fig. 5. Heat gain source in the building

Blind covering area has a negative SRC towards EUI cooling, which means the cooling energy decreases when the window has more area covered with blind. When there is no shading installed on the window, the thermal convection current will flow through the window unobstructed. As the blind is installed behind the window, the flow of thermal fluid velocity become obstructed (Fig. 6). Thus, it reduces the thermal convection rate. This results in less heat entering the building that increases the thermal load. Therefore, the cooling energy reduces. This effect is called the chimney effect that is also demonstrated by Shahid and Naylor [17].

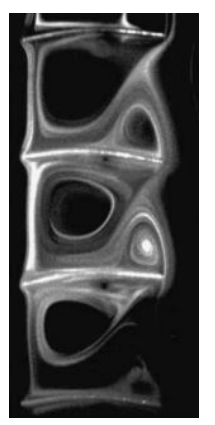

Fig. 6. Change of fluid velocity in venetian blind [17]

In contrast, the blind angle shows a positive SRC towards the EUI for cooling. This finding implies that when the blind angle is tilted upward to $80^{\circ}$ or downward to $-80^{\circ}$, the cooling energy increases. As the blind is exposed to the sun, the surface temperature of the blind rises. Thus, the blind radiates heat into the room and increases the cooling load. The amount of heat depends on the area that receives solar exposure.

Fig. 5 shows the change in the projected area when the blind angle tilted from $20^{\circ}$ to $60^{\circ}$. This is the area that receives solar exposure. As the blind is tilted to a higher degree, the projected area increases which also gives a higher probability that the blind surface exposed to solar radiation and add heat gain to the building.
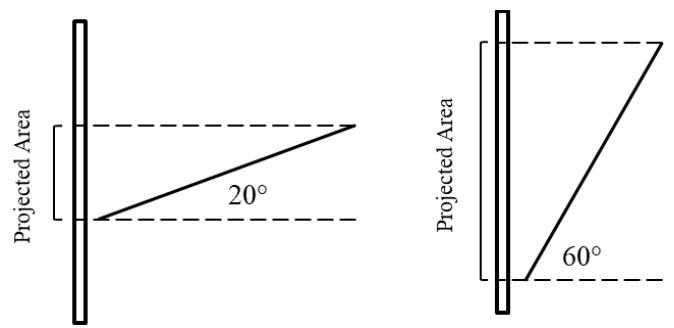

Fig. 7. Change in the projected area when the blind is tilted from $20^{\circ}$ to $80^{\circ}$

However, for both blind covering area and blind angle, the value of SRC is small, which is around 0.03. This indicates the EUI cooling is not significantly affected by this factor. To evaluate this finding, $\mathrm{U}$-value of the window with and without venetian blind are compared. Without venetian blind, the UValue is $1.8 \mathrm{~W} / \mathrm{m}^{2} \mathrm{~K}$. Whereas, the $\mathrm{U}-$ Value with venetian blind can be reduced to $0.3 \mathrm{~W} / \mathrm{m}^{2} \mathrm{~K}$. There might be another factor that increases the performance of solar shadings, such as lower U-Value and SHGC of glazing.

It can be observed from Fig. 8, that the SRC values of EUI for Lighting and SDA are contradictory for both shading parameters. When indoor daylight illuminance values are high, lighting energy will decrease. As the blind is tilted, less daylight enters the space, therefore the illuminance decreases, and more lighting fixtures switch on. Comparing the two inputs, the blind angle has a more significant impact than blind covering area. 

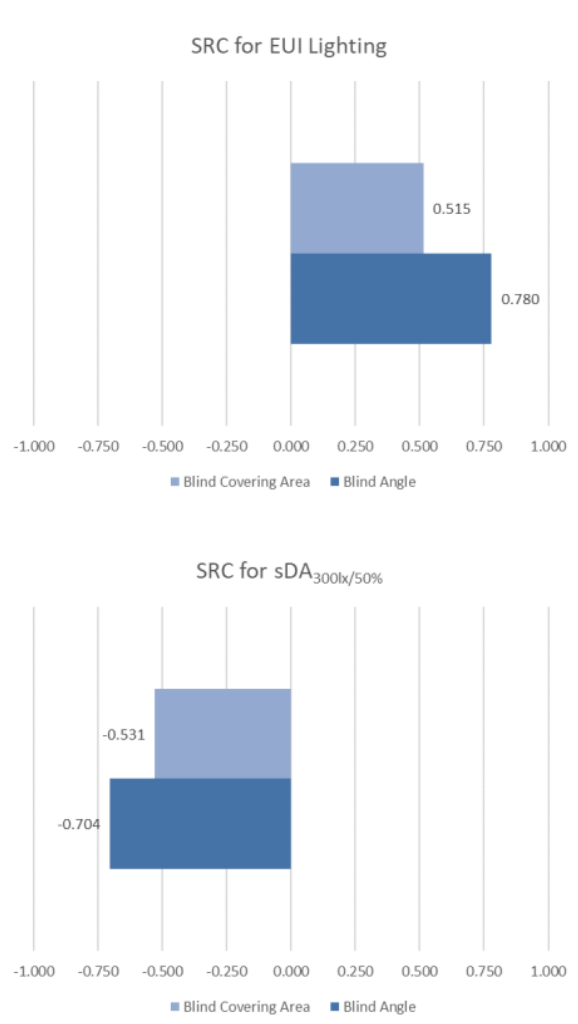

Fig. 8. SRC value for EUI Lighting and sDA

For the DGPs indicator, the results show a similar trend with sDA (Fig. 9). When the blind is tilted upward to $80^{\circ}$ or downward to $-80^{\circ}$, DGPs values are decreasing because direct sunlight is not reflected to the observer. SRC values are also higher for blind angle than blind covering area since the blind angle is better for directing sunlight. However, with the combination of these parameters, daylight is more likely to be controlled to increase building performance.

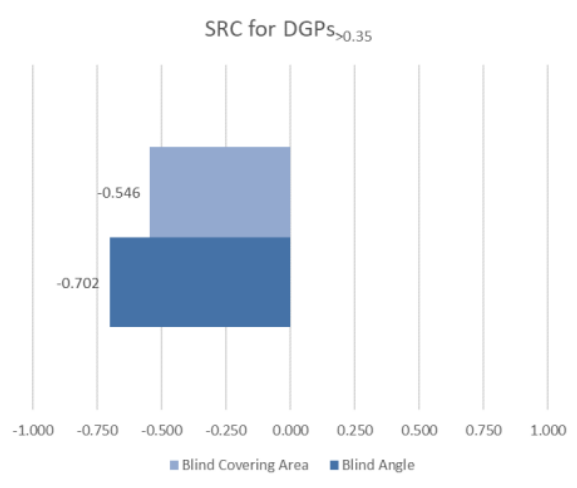

Fig. 9. SRC value for DGPs

\section{CONCLUSION}

This paper presents a sensitivity analysis of four building performance indicators, namely EUI cooling, EUI lighting, spatial daylight autonomy (sDA), and daylight glare probability simplified (DGPs). The method for sensitivity analysis is the standardized regression coefficient (SRC). By comparing the magnitude of SRC, the most significant parameter can be defined. Based on the result, the SRC for the blind angle is higher than blind covering area for EUI lighting, sDA, and DGPs with $0.78,0.704$, and 0.702 , respectively. It can be concluded that blind angle is more influencing parameter than blind covering area. Meanwhile, both blind angle and blind covering area not significantly affect EUI cooling since the SRC is around 0.03. This study is a preliminary analysis for dynamic shading device optimization using venetian blind for tropical climate in the open-plan office.

\section{ACKNOWLEDGMENT}

This research was supported by ITB Multidisciplinary Research 2019.

\section{REFERENCES}

[1] R. Jing, M. Wang, R. Zhang, N. Li, and Y. Zhao, “A study on energy performance of 30 commercial office buildings in Hong Kong," Energy and Buildings, vol. 144, pp. 117-128, Jun. 2017.

[2] C. Reinhart, Effects of interior design on the daylight availability in open plan offices. 2002.

[3] Y.-C. Chan and A. Tzempelikos, "Efficient venetian blind control strategies considering daylight utilization and glare protection," Solar Energy, vol. 98, pp. 241-254, Dec. 2013.

[4] M. B. Hirning, G. L. Isoardi, and I. Cowling, "Discomfort glare in open plan green buildings," Energy and Buildings, vol. 70, pp. 427-440, Feb. 2014.

[5] M. A. Anthony, A. T. Hibatullah, R. A. Mangkuto, dan R. T. Atmodipoero, "Optimization study of visual comfort and daylight availability at CADL ITB," DIMENSI (Journal of Architecture and Built Environment); Vol 43, No 2, 2016.

[6] R. Shan, "Optimization for Heating, Cooling and Lighting Load in Building Façade Design,” Energy Procedia, vol. 57, pp. 1716-1725, Jan. 2014.

[7] Y.-W. Lim, M. H. Ahmad, and D. R. Ossen, "Internal Shading for Efficient Tropical Daylighting in Malaysian Contemporary High-Rise Open Plan Office," Indoor and Built Environment, vol. 22, no. 6, pp. 932-951, Oktober 2012.

[8] G. Rapone, O. Saro, dan G. Zemella, "Multi-objective optimisation of external shading devices for energy efficiency and visual comfort," IBPSA Proceeding, 2013.

[9] Badan Standar Nasional [National Standard Agency], "SNI $036197-$ 2011: Konservasi energi pada sistem pencahayaan [Energy conservation in lighting systems]," Standar Nasional Indonesia, 2011.

[10] American Society of Heating, Refrigerating and Air-Conditioning Engineers (ASHRAE), "ASHRAE STANDARD Ventilation for Acceptable Indoor Air Quality ANSI/ASHRAE Standard 62.1-2007 (Supersedes ANSI/ASHRAE Standard 62.1-2004) Includes ANSI/ASHRAE Addenda listed in Appendix I," 2007.

[11] IESNA, "LM-83-12 IES Spatial daylight autonomy (sDA) and annual sunlight exposure (ASE)," N. Y. NY USA IESNA Lighting Measurement, 2012.

[12] J. Wienold, "Dynamic simulation of blind control strategiesfor visual comfort and energy balance analysis," Building Simulation, 2007.

[13] J. Wienold, "Dynamic daylight glare evaluation." Proc., 11th International IBPSA Conference Building Simulation 2009, BS 2009, 944-951, 2009.

[14] C. F. Reinhart and J. A. Jakubiec, "The 'adaptive zone' - A concept for assessing discomfort glare throughout daylit spaces," Light. Res. Technol., vol. 44, no. 2, pp. 149-70, 2012.

[15] Larry D. Schroeder, David L. Sjoquist, Paula E. Stephan, "Understanding regression analysis, "Sage Publications, pp. 31-32, 1986.

[16] M. Bremer, "Multiple Linear Regression," Cornell University, pp. 19, 2012. 
PRESS

[17] H. Shahid and D. Naylor, "Energy performance assessment of a window with a horizontal Venetian blind," Energy and Buildings, vol. 37, no. 8, pp. 836-843, Agu 2005 . 